
\title{
Reseracth Sulure \\ Influence of Aerosols on Atmospheric Gravity Waves at an Urban Tropical Location
}

\section{Soumyajyoti Jana}

Indian Space Research Organisation

\section{Gargi Rakshit}

University of Calcutta

Animesh Maitra ( $\nabla$ animesh.maitra@gmail.com )

University of Calcutta https://orcid.org/0000-0002-9412-6995

\section{Research Article}

Keywords: Influence of Aerosols, Atmospheric Gravity Waves, Urban Tropical Location, temperature, tropical metropolis

Posted Date: December 30th, 2021

DOI: https://doi.org/10.21203/rs.3.rs-1121047/v1

License: (9) This work is licensed under a Creative Commons Attribution 4.0 International License. Read Full License 


\section{Influence of Aerosols on Atmospheric Gravity Waves at an Urban Tropical Location}

\section{Soumyajyoti Jana ${ }^{1}$, Gargi Rakshit ${ }^{2}$, and Animesh Maitra ${ }^{2}$}

${ }^{1}$ Space Physics Laboratory, Vikram Sarabhai Space Centre, Indian Space Research Organisation, Thiruvananthapuram, India

${ }^{2}$ Institute of Radio Physics and Electronics, University of Calcutta, 92, AcharyaPrafulla Chandra Road, Kolkata 700009

Corresponding author: AnimeshMaitra (animesh.maitra@gmail.com) 


\section{Highlights:}

- Elevated aerosol layer creates temperature and wind perturbations above boundary layer (1.6-4 km) during pre-monsoon.

- The associated total gravity wave energy increases in the upper tropospheric region between 6 and $10 \mathrm{~km}$.

- The presence of heat-absorbing aerosols promotes lower atmospheric oscillation which propagates upward. 


\begin{abstract}
The elevated layer of heat-absorbing pollutant aerosols causes temperature perturbations in the pre-monsoon period above the boundary layer height $(1.6-4 \mathrm{~km})$ as observed over a polluted tropical urban location Kolkata $\left(22^{\circ} 34^{\prime}\right.$ N, $88^{\circ} 22^{\prime}$ E) during 2007-2016. Satellite observations of different types of aerosols show an increase in aerosol extinction coefficient around 1.6-4 km altitude, enhancing the perturbations in both temperature and wind profiles at that height. The opposing air mass movement within and above the boundary layer, which is strengthened by elevated heat-absorbing aerosols, is illustrated by height profiles of atmospheric vorticity and divergence. This results in higher Brunt-Vaisala frequencies indicating increased atmospheric oscillations. Consequently, atmospheric gravity waves, which manifest the temperature and wind profile perturbations, have enhanced energy in the upper troposphere $(6-10 \mathrm{~km})$. Based on multitechnique observations consisting of radiosonde, space-borne lidar and model data, this study reveals the interactions between aerosol and other atmospheric processes such as temperature variations and wind perturbations, which affect the atmospheric instability and increase gravity wave activities during the pre-monsoon period over a tropical metropolis.
\end{abstract}

\title{
1 Introduction
}

Atmospheric gravity waves $(\mathrm{GW})$, manifesting the interaction of Earth's gravity and restoring buoyancy force of the air parcel in the atmosphere, generally originate in the lower troposphere (LT). Convection and orographic disturbances in the LT trigger generation of GW energy which propagates in the middle and upper atmosphere impacting the atmospheric general circulation (Alexander \& Holton, 1997; Alexander et al., 1995; Venkat Ratnam et al., 2004; Holton, 1983). Thus, observations of lower atmospheric parameters are crucial to understand the atmospheric gravity waves and their impacts on the atmospheric dynamics (Lane et al., 2003; Geller \& Gong, 2010). The GW energy is estimated from temperature and wind profile perturbations in the lower troposphere, which amplify in magnitude as they propagate into the upper atmosphere and transport momentum to higher altitudes (Fritts and Alexander, 2003; Ern et al., 2014). Atmospheric gravity wave activities during deep convection over the tropics are often associated with troposphere stratosphere exchange processes resulting in an intrusion of water vapour from the upper troposphere (UT) to the lower stratosphere (LS) and ozone from LS to UT (Ravindra Babu et al., 2015; Ray \& Rosenlof, 2007; Rakshit et al., 2018; Jana et al., 2020). Hence it is imperative to investigate the perturbation in temperature and wind profiles and the resultant GW genesis in the lower troposphere under different atmospheric conditions.

The presence of an elevated aerosol layer above the atmospheric boundary layer (ABL) is a usual phenomenon over urban tropical locations like Kolkata during the pre-monsoon period (Niranjan et al., 2007; Satheesh et al., 2008). Previous studies have revealed that the abundance of aerosol above the boundary layer caused the aerosol induced warming process at that height resulting in a significant meridional wind gradient (Satheesh et al., 2008). Heat absorbing aerosols perturb the Earth's radiation budget by absorbing the solar radiation ((IPCC), 2001, Jacobson, 2001). Kolkata being a tropical metropolis, the pollutant aerosols which dominate the present location can go above the normal boundary layer due to pre-monsoon convection, and trapping of aerosol occur at that height causing perturbation in temperature profile (Talukdar et al., 2017; Jana et al., 2019). Changes in temperature profile also impact the wind profile resulting in increased wind perturbations. The phenomena of enhanced warming due to elevated aerosol above the atmospheric boundary layer were reported earlier (Satheesh et al., 2008; Thornhill et al., 2018; Suresh Babu et al., 2011). However, increased temperature perturbations due to aerosol 
induced warming and the subsequent effect on GW activities at higher altitudes is yet to be reported in the open literature. The present study investigates an increase in temperature perturbation in Kolkata $\left(22^{\circ} 34^{\prime} \mathrm{N}, 88^{\circ} 22^{\prime} \mathrm{E}\right)$ caused by an abundance of heat-absorbing aerosols above the atmospheric boundary layer. Subsequently, GW activities in the UT have been studied using radiosonde data. The dominant spectral component of GW is estimated using LombScargle spectral analysis from the temperature and wind component (Scargle, 1982).

Another consequence of the abundance of heat-absorbing aerosols is the change of circulations represented by wind's relative vorticity and divergence (Lau, 1979). The presence of heat-absorbing aerosols can also change circulation, as indicated by the relative vorticity and divergence of wind (Lau, 1979). The effect of elevated aerosol above the boundary layer on the vorticity and divergence profiles has been investigated from European Centre for Medium-Range Weather Forecasts (ECMWF) data, relating the lower atmospheric circulation to the gravity wave energy at the upper atmosphere.

In summary, the present study aims at: i) identifying the aerosol type in elevated aerosol above the atmospheric boundary layer over Kolkata during the pre-monsoon period in comparison to other seasons during 2007 to 2016, ii) estimating the mean perturbation in the temperature and wind profile due to enhanced aerosol concentration around 1.6 to $4 \mathrm{~km}$ for the considered period of 10 years, iii) assessing the GW energy in the upper troposphere in the height range 6 to $10 \mathrm{~km}$, iv) investigating the vorticity, divergence and related Brunt-Vaisala frequency variation above boundary layer height $(>1.6 \mathrm{~km})$, and finally, iv) identifying the dominant vertical wavelength responsible for enhanced GW energy at the heights $6-10 \mathrm{~km}$. The present manuscript has five sections: Data and Methodology in Section 2, Results of the investigation in Section 3, and Discussions and Conclusions in Sections 4 and 5, respectively.

\section{Data and Methodology}

The present study has been carried out using in-situ and space-borne observations and model data as described below.

The temperature and wind perturbations and atmospheric GW energy are estimated from the radiosonde data, available twice daily from the data archive of the University of Wyoming for the location of Kolkata during the period 2007-2016. The wind velocity and bearing data, from radiosonde are used to estimate zonal and meridional wind components. The vertical profiles of temperature $(T)$, zonal $(u)$ and meridional $(v)$ wind data are interpolated for a uniform altitude resolution of $100 \mathrm{~m}$. Then the background profiles of temperature, zonal and meridional

$(\bar{u}, \bar{v}, \bar{T})$ wind data are obtained by fitting a second-order polynomial to the respective profiles. The perturbation profiles $\left(T^{\prime}, u^{\prime}, v^{\prime}\right)$ are then obtained by subtracting the background profile from the individual profile. Finally, the potential energy $\left(E_{p}\right)$ and kinetic energy $\left(E_{k}\right)$ are calculated using the following relations (Tsuda et al., 2004; Vincent and Alexander, 2000).

$$
\begin{aligned}
E_{p} & =\frac{1}{2}\left[\left(\frac{g}{N}\right)^{2} \overline{\left(\frac{T^{\prime}}{\bar{T}}\right)^{2}}\right] \\
E_{k} & =\frac{1}{2}\left[\overline{u^{\prime 2}}+\overline{{v^{\prime 2}}^{2}}\right] \\
N^{2} & =\frac{g}{\theta} \frac{d \theta}{d z} \\
\theta & =T\left(\frac{P_{0}}{P}\right)^{R / c_{p}}
\end{aligned}
$$


Here $g$ is the acceleration due to gravity, $z$ is altitude, $\theta$ is potential temperature and $N$ is the Brunt-Väisälä frequency (Stull, 1995; Rakshit et al., 2018; Jana et al., 2020). Here $P_{0}$ and $\mathrm{P}$ are the standard surface pressure and pressure at different height respectively. $R$ is the gas constant of air, and $c_{p}$ is the specific heat capacity at a constant pressure $\frac{R}{c_{p}}=0.286$ for air. The temperature and wind perturbations and resultant GW kinetic and potential energy are presented to reveal the seasonal behaviour of GW energy distribution in the upper troposphere for the height range 6 to $10 \mathrm{~km}$ over Kolkata. The presence of water vapour above the boundary layer in the height range of 1.6 to $4 \mathrm{~km}$ is estimated from the radiosonde data.

The extinction coefficient profiles of total aerosols, dust aerosols, pollutant dust aerosols and smoke particles at $532 \mathrm{~nm}$ from Cloud-Aerosol Lidar and Infrared Pathfinder Satellite Observations (CALIPSO) satellite are utilized to indicate the characteristics of the aerosol environment above the atmospheric boundary layer over Kolkata. The monthly extinction coefficient data available at a spatial resolution of $2^{\circ} \times 5^{\circ}$ around the present study location, available from the website of NASA (https://eosweb.larc.nasa.gov/project/calipso/cloudfree_aerosol_L3 lidar_table), are used. The vertical resolution of aerosol extinction coefficients of CALIPSO data is $60 \mathrm{~m}$.

The temperature, divergence and relative vorticity profile at 37 pressure levels and 60 model levels are obtained from European Centre for Medium-Range Weather Forecasts (ECMWF) data at a spatial resolution of $0.5^{\circ} \times 0.5^{\circ}$ around Kolkata (https://apps.ecmwf.int/datasets/data/interim-full-moda/levtype=ml/). The mean vertical resolution of the ECMWF 60 model level data is around $400 \mathrm{~m}$ in the height range of $1.6-4 \mathrm{~km}$ considered in the present study. The ECMWF 37 pressure level data of temperature has also been used to estimate Brunt-Vaisala frequency.

Absorbing Aerosol Index (AI) daily data with a spatial resolution of $1^{\circ} \times 1^{\circ}$ obtained from Global Ozone Monitoring Experiment-2 (GOME-2) on MetOp-A platform at $340 \mathrm{~nm}$ and 380 nm. Positive AI values indicate the presence of heat-absorbing aerosol particles.

\section{Results}

Pre-monsoon elevated aerosol can significantly affect temperature and wind perturbation profiles and subsequent GW activities compared with the monsoon (June-September), postmonsoon (October-November), and winter (December-February) during 2007-2016.

\subsection{Aerosol interaction with gravity waves}

The seasonal mean profiles of aerosol extinction coefficient (AEC) during different seasons in the height range of 1.6 to $4 \mathrm{~km}$ over Kolkata are shown in Figure 1. During the premonsoon season (March to May), AEC profiles at $532 \mathrm{~nm}$ obtained from CALIPSO data show a significantly higher value compared to other seasons over Kolkata (Figure 1(a)). The monthly variation of mean absorbing aerosol index (AI) values during 2007-2016 retrieved from MetOpA satellite also show enhanced values during the pre-monsoon months compared to other months indicating the abundance of heat-absorbing aerosols during this time (Figure 1(b)). 

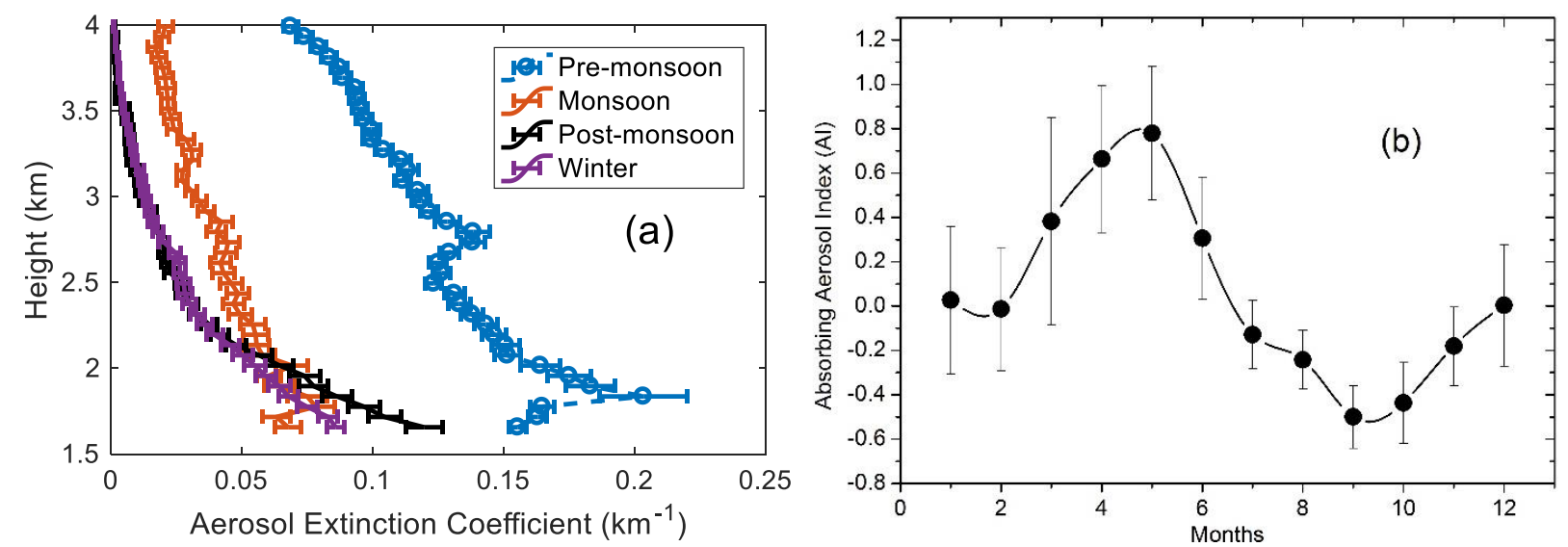

Figure 1.(a) The vertical profiles of aerosol extinction profile $(550 \mathrm{~nm})$ from CALIPSO, and (b) seasonal variation of the aerosol index (AI) over Kolkata from 2007 to 2016.
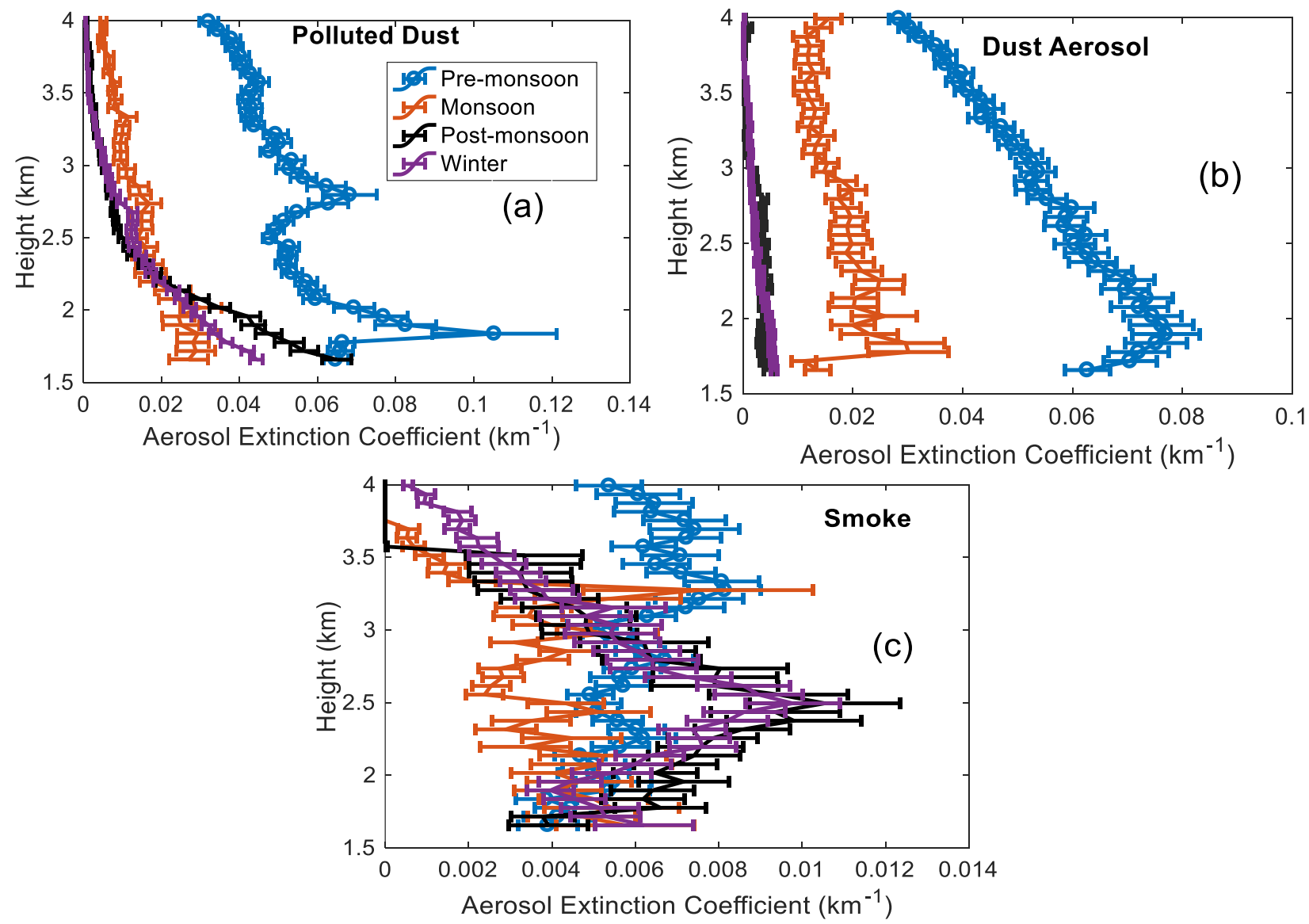

Figure 2. The vertical profiles of aerosol extinction coefficient for: (a) Dust, (b) Polluted dust and (c) Smoke particles at $532 \mathrm{~nm}$.

Figure 2 shows the height profiles of different types of aerosol, such as the pollutant dust, smoke and dust at $532 \mathrm{~nm}$ produced by CALIPSO, which account for the enhanced AEC during the premonsoon season over Kolkata. A dominance of dust and pollutant dust particles in the height range 1.6 to $4 \mathrm{~km}$ is observed, which should be responsible for the enhanced AEC values during 
the pre-monsoon period over Kolkata (Figure 2(a), (b)). Hence, the abundance of heat-absorbing aerosols like pollutant dust and dust particles above the boundary layer during the pre-monsoon period perturb the temperature profile (Yue et al., 2010; Gu et al., 2016). Against this backdrop, the absolute mean perturbations in the temperature $\left(\frac{T^{\prime}}{\bar{T}}\right)$ profiles are obtained during 2007-2016 in the height range of 1.6-4 km, as shown in Figure 3(a). The temperature perturbations show a significant increase in the pre-monsoon period compared to other seasons (Figure 3(a)). The temperature variation is often associated with a change in background wind pattern. Hence the zonal $(u)$ and meridional $(v)$ wind perturbations are estimated from wind velocity and bearing, as shown in Figure 3(b), (c). Wind perturbations, mainly the meridional wind components, show an enhancement in perturbations in the pre-monsoon period.
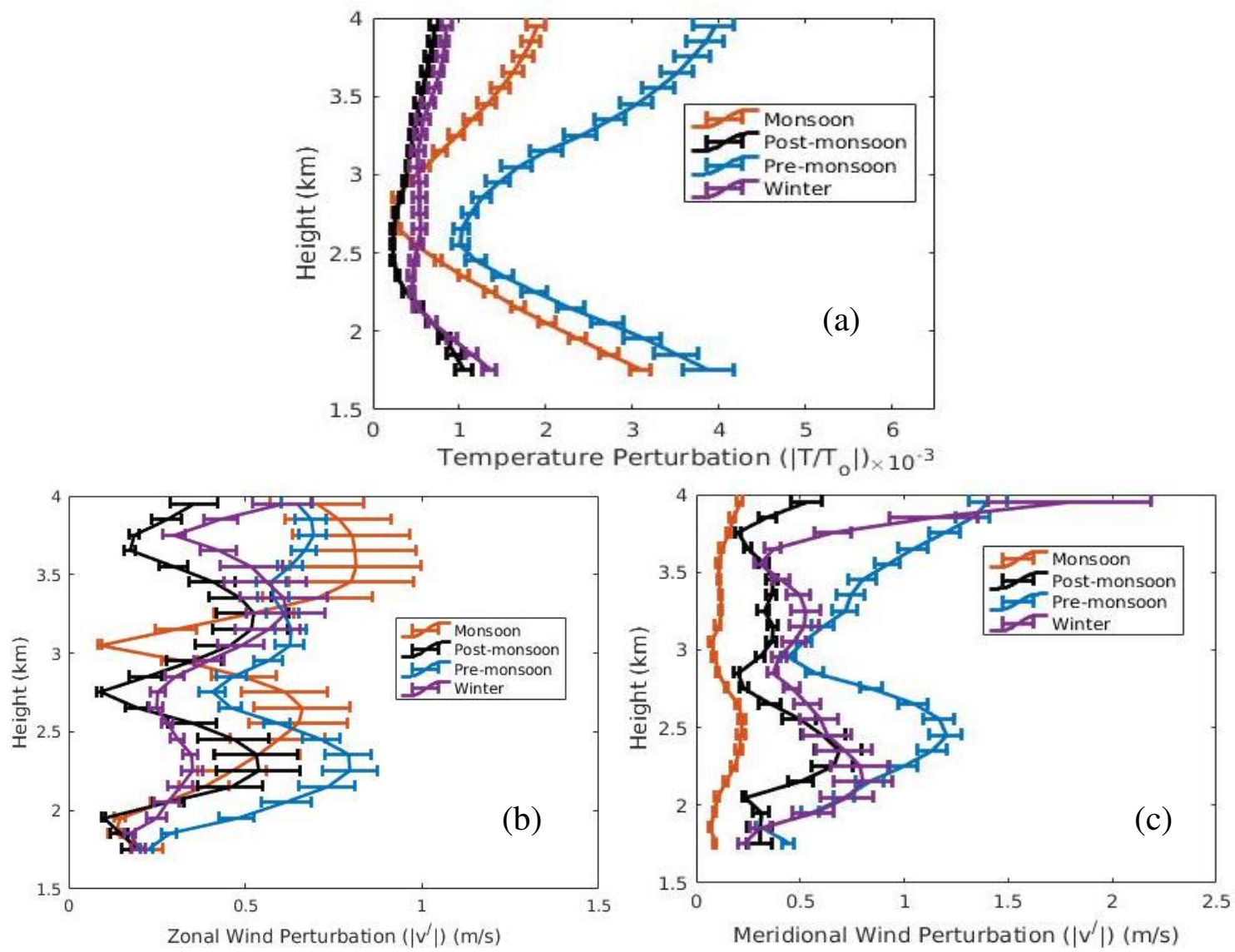

Figure 3. The vertical profiles of absolute (a) temperature perturbation, (b) zonal wind perturbation, and (c) meridional wind perturbation.

The enhanced perturbations created in the temperature and wind profiles above the boundary layer will increase in magnitude as they propagate upward, causing an increase in gravity wave energy at higher altitudes in a relatively less dense atmosphere. Accordingly, we estimate the average energy content in the upper troposphere $(6-10 \mathrm{~km})$ using radiosonde data following the methodology described in Section 2. According to Figure 4, the GW energy during the premonsoon season is significantly higher than the other seasons. The enhanced temperature and 
wind perturbations that occur during the pre-monsoon period in UT are due to the increased GW potential and kinetic energy caused by heat-absorbing aerosols above the boundary layer.
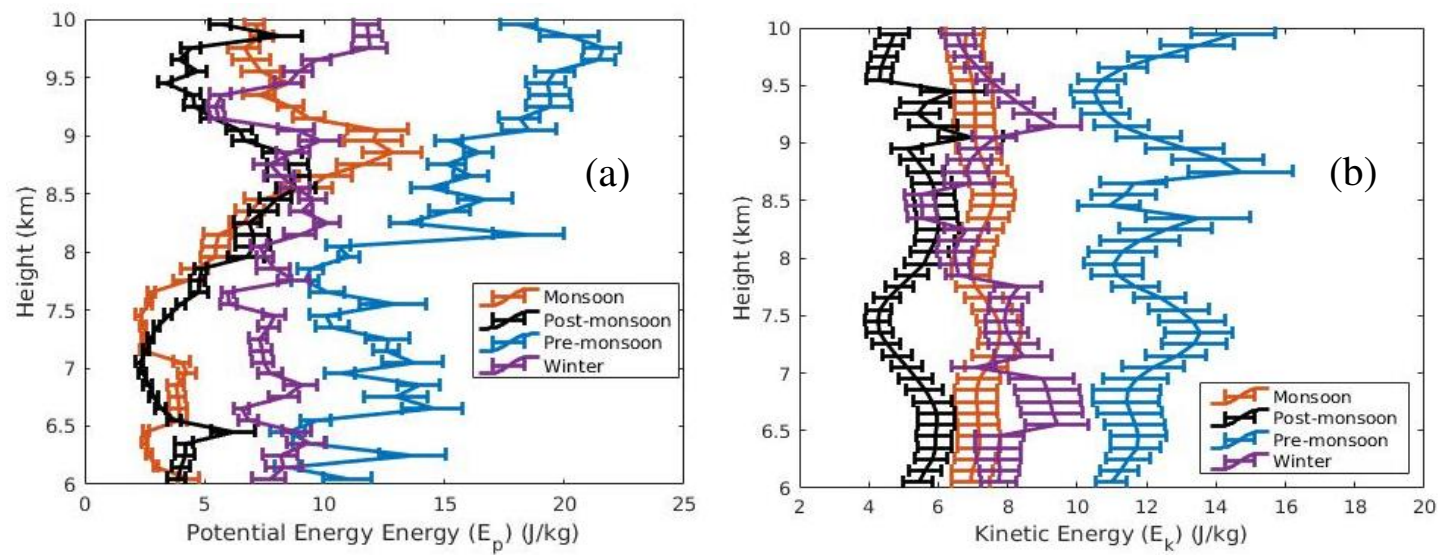

Figure 4. The vertical profiles of (a) potential energy, and (b) kinetic energy in the upper troposphere (6$10 \mathrm{~km})$.

Figure 5 shows a seasonal variation of the extinction coefficient values as well as the total GW energy (kinetic plus potential). In this case, the total GW energy is averaged within a height range of $6-10 \mathrm{~km}$ and the AEC is averaged within a height range of $1.6-4 \mathrm{~km}$.

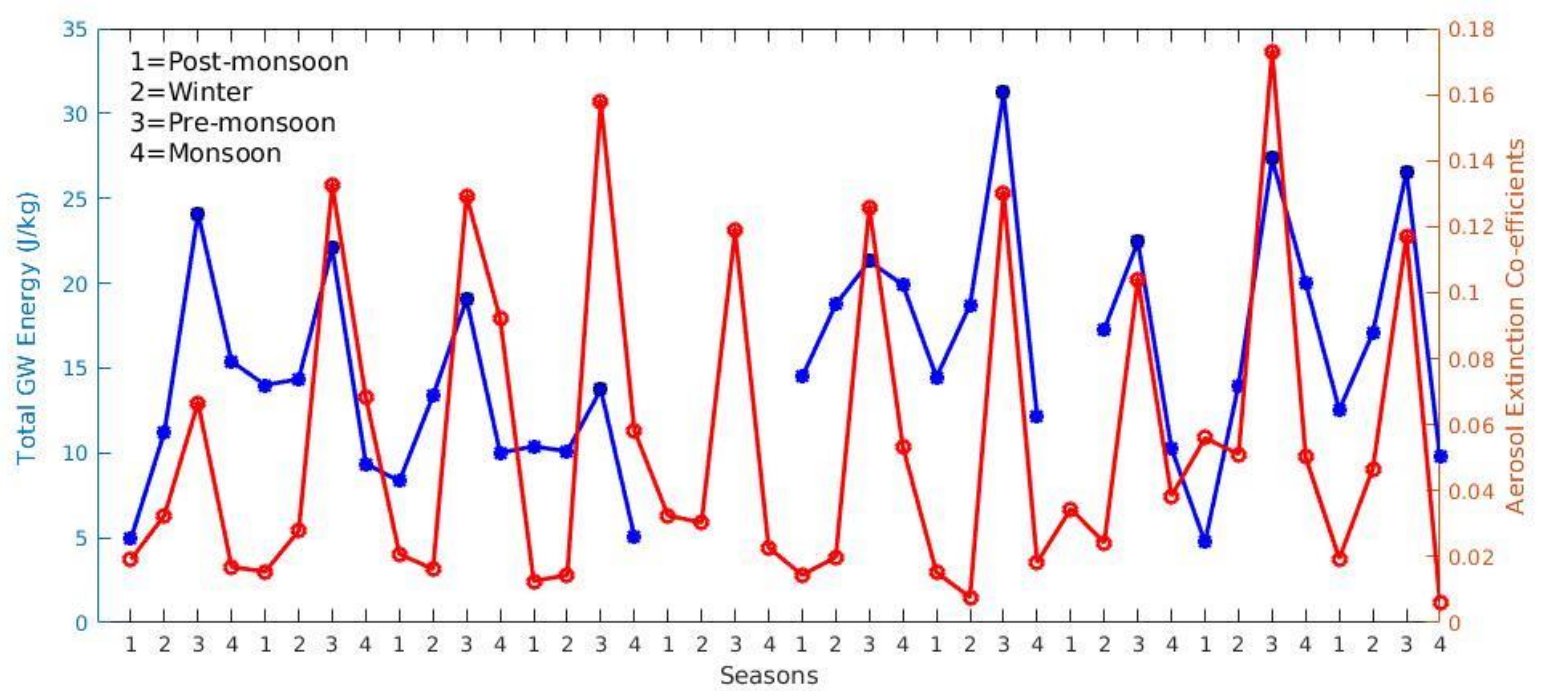

Figure 5.The seasonal variation of height averaged $(6-10 \mathrm{~km})$ total $\mathrm{GW}$ energy (in blue line), and height averaged (1.6-4 km) extinction coefficient values (in red line) starting from 2007 to 2016.

Figure 5 depicts that the total GW energy in the UT $(6-10 \mathrm{~km})$ follows the variation of mean aerosol extinction coefficient values above the ABL (1.6-4 km) during 2007-2016. The peaks in the seasonal curve correspond to the pre-monsoon peaks. There is a data gap of radiosonde measurements during 2011. 
To investigate the increase in the gravity wave energy in the pre-monsoon period, we have analyzed temperature lapse rate, vorticity, and divergence of air mass flow, which are indicators of the atmospheric stability and circulation pattern at different heights . In Figure 6(a), it can be seen that the atmospheric lapse rate (temperature gradient) shows a significant reduction at and above the boundary layer height $(>1.6 \mathrm{~km})$ which is caused by the presence of the elevated layer of pollutant aerosols and dust (Figure 2). This reduces the instability at this height and lowers the vertical transport seen from both divergence and vorticity data (Figure 6 (b),(c)). It can be seen from Figure 6(b) and (c) that within the boundary layer vorticity (divergence) is positive (negative) during pre-monsoon and monsoon. Whereas above the boundary layer height a reverse scenario prevails during pre-monsson season only. The negative divergence (indicating convergence of air mass) and positive vorticity (implying cyclonic air motion) are responsible for upward motion of air within the boundary layer (Wallace and Hobbs, 2006). However, above the boundary layer height positive divergence and negative vorticity (anti cyclonic air motion) causes subsidence of air mass (Wallace and Hobbs, 2006). So during the pre-monsoon period, an air parcel experiences opposite forces within and above the boundary layer region, which results in oscillations of airmass around the boundary layer. This results in higher Brunt-Vaisala frequency in the height range $\sim 2-4 \mathrm{~km}$ (Figure 6(d)). Other seasons, however, do not show such opposite directional airmass flow within and above boundary layer height.
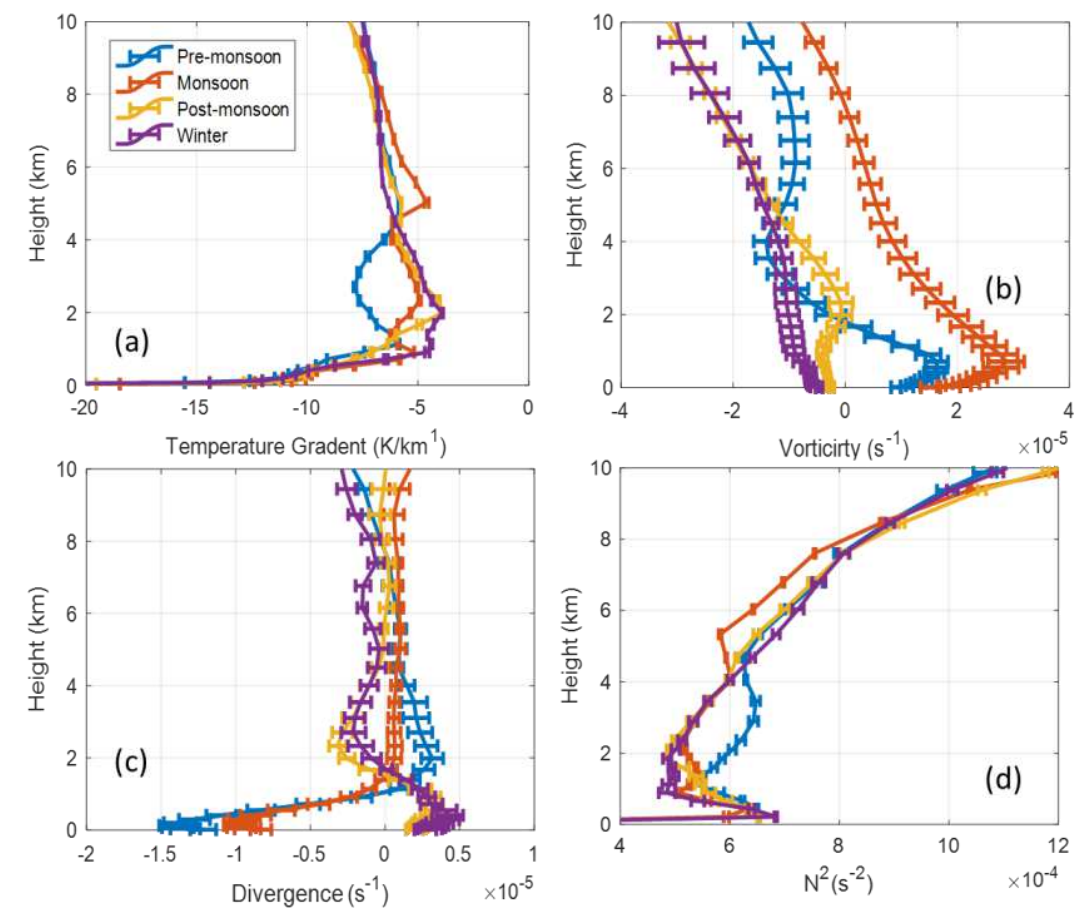

Figure 6. Average (a) temperature height gradient, (b) divergence, (c) vorticity and (d) Brunt-Vaisala frequency during four seasons. 


\subsection{Dominant vertical wavelength in the upper troposphere during pre-monsoon over Kolkata}

The predominant vertical wavelength of GW in height range 6 to $10 \mathrm{~km}$ prevailing over Kolkata is estimated following the Lomb-Scargle method of spectral analysis (Scargle, 1982; Jana et al., 2020). The vertical wavelengths have been obtained from the temperature, zonal and meridional wind perturbations. The spectral analysis reveals that the vertical wave number of around 1 cycle/km is dominant in the UT $(6-10 \mathrm{~km})$ during pre-monsoon over Kolkata as seen from Figure 7.
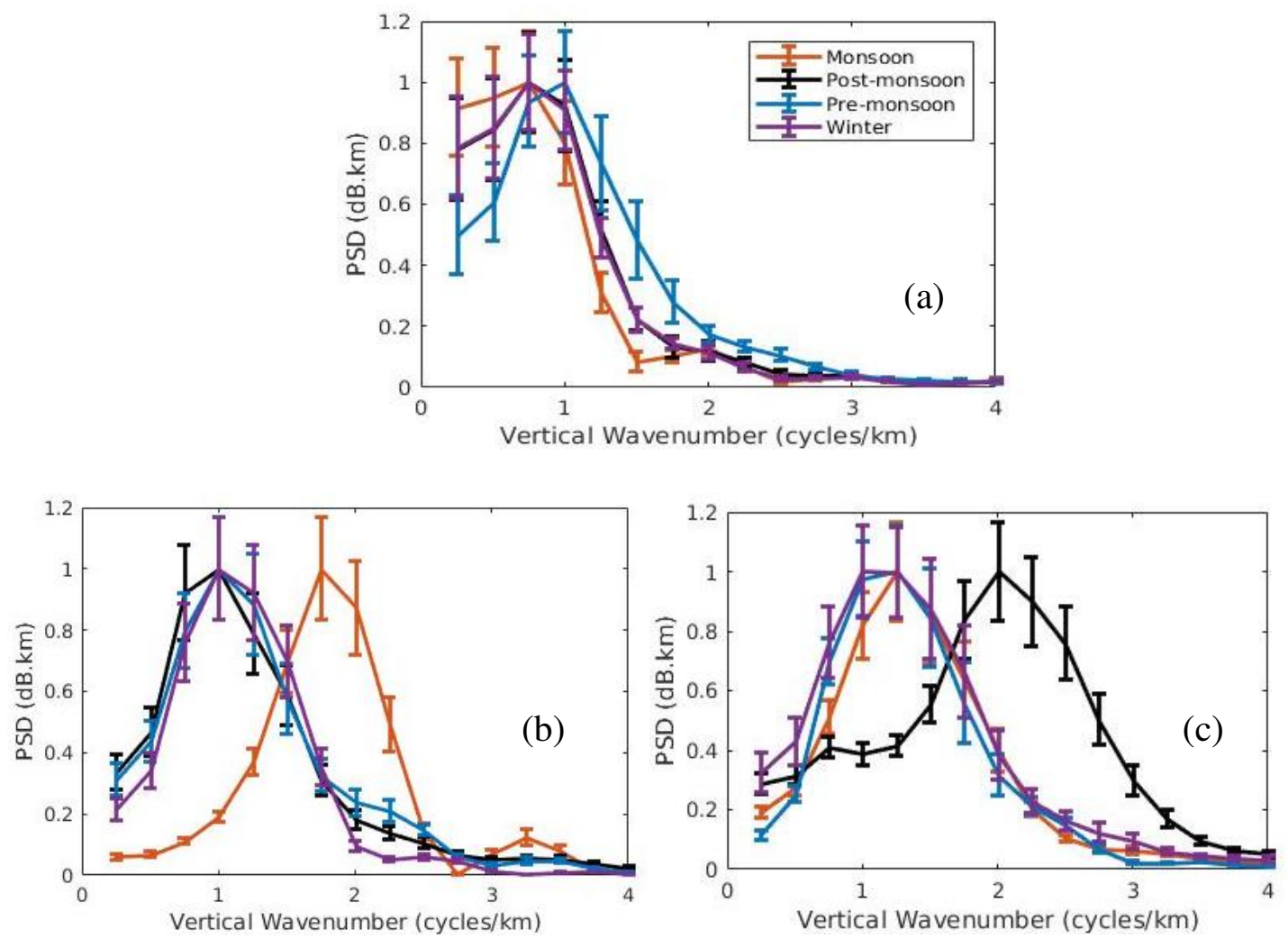

Figure 7. Mean power spectral density of gravity waves in the upper troposphere over Kolkata as revealed from (a) temperature, (b) zonal wind, and (c) meridional wind components. These show that the dominant spectral components occur at wavenumber around 1 cycle $/ \mathrm{km}$.

\section{Discussions}

The present investigation reveals the effects of elevated aerosol concentration around 1.6 to $4 \mathrm{~km}$ on the temperature and wind perturbations, GW activities over a tropical metropolis, Kolkata, during the pre-monsoon season based on long term data during 2007-2016. The premonsoon scenario is presented in comparison to other seasons, namely monsoon, post-monsoon and winter months. The study shows the dominance of dust and polluted dust particles in the 
elevated aerosol layer above the ABL height as evident from the aerosol extinction coefficient profiles obtained from CALIPSO observations at $532 \mathrm{~nm}$. The pre-monsoon months over Kolkata are characterized by increased mean absorbing aerosol index values derived from spaceborne observations of MetOp-A satellite, indicating the dominance of heat-absorbing aerosols (De Graaf et al., 2005). In addition, the present results are consistent with the findings of Nair et al. (2016), which revealed the dominance of heat-absorbing aerosols in the free troposphere of western India during the pre-monsoon. The GW activity is found to be maximum in the premonsoon showing highest energy among the other seasons (Figure 4-5). The probable explanation of the increase in GW energy in the pre-monsoon period is the presence of oscillation in airmass due to opposite directional air flow above and within boundary layer. The elevated layer of aerosol above the boundary layer reduces temperature lapse rate (Figure 6(a)) hindering the normal uplift of air and promotes outflow or divergence of air from that region. Within the boundary layer, positive (cyclonic) vorticity, shown in Figure 6(b), causes upward movement of air that reverses above boundary layer due to negative vorticity (Wallace and Hobbs, 2006). Figure 8 gives a schematic presentation of the generation mechanism of oscillation around boundary layer height in the pre-monsoon period.

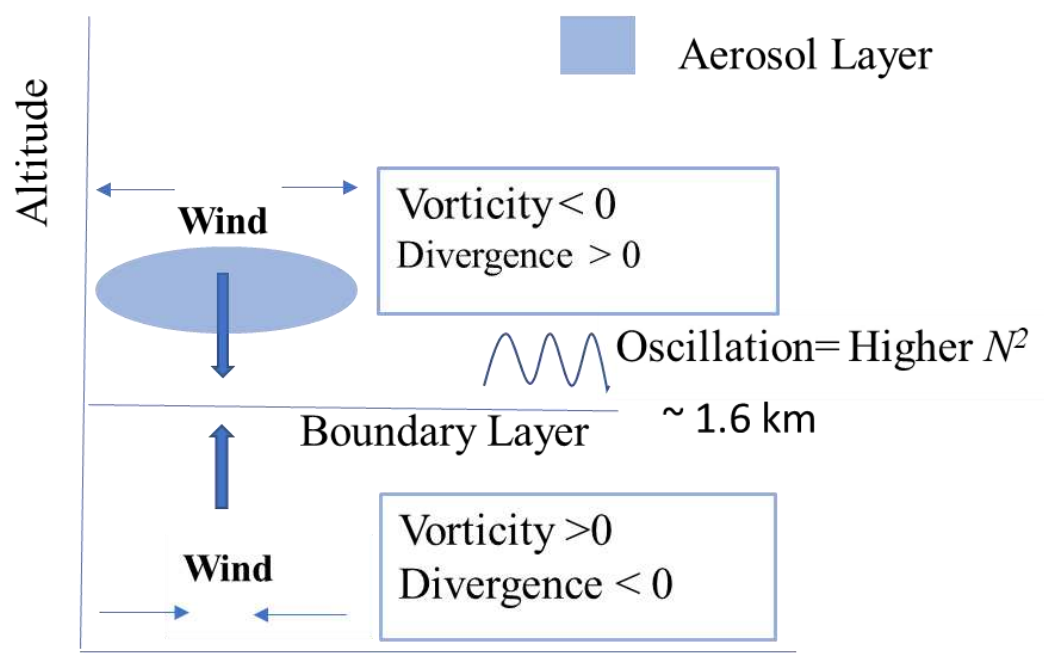

Earth's surface

Figure 8. The schematic presentation of pre-monsoon wind movement across the boundary layer which promotes atmospheric oscillation over Kolkata.

So the enhanced aerosol concentration during the pre-monsoon season above the ABL has an significat role in perturbing temperature and wind compared to other seasons. The perturbations in the temperature and wind flow have amplified atmospheric oscillation in lower troposphere which propagates at higher altitudes to enhance the GW kinetic and potential energy in the height range 6 to $10 \mathrm{~km}$, as estimated from radiosonde profile data over Kolkata. The spectral analysis of this GW using the Lomb-Scargle method has shown that the vertical wavenumber of around 1 cycles $/ \mathrm{km}$ is dominant in this height range over Kolkata (Scargle, 1982). 


\section{Conclusions}

The present study shows that aerosols significantly impact temperature and wind perturbations above the boundary layer in the height range 1.6-4 km over Kolkata, which is located in a tropical zone, for the period 2007 to 2016. Perturbations are amplified and cause an enhancement in gravity wave energy in the upper troposphere $(6-10 \mathrm{~km})$. The abundance of heat-absorbing aerosols like polluted dust and dust particles influences heat flow in the pre-monsoon season, contributing to the higher gravity wave energy in the upper troposphere. A vertical wavenumber of around 1 cycle $/ \mathrm{km}$ dominates the energy density spectrum of gravity waves in the upper troposphere during the pre-monsoon period. The study has implications in the context of changing atmospheric circulation patterns due to enhanced anthropogenic activities.

\section{Acknowledgements}

This work has been supported by the grants under the projects entitled (i) "Studies on aerosol environment at Kolkata located near the land-ocean boundary as a part of ARFI network under ISRO- GBP" (Grant No: SPL:GBP:ARFI:37), (ii) "Council of Scientific and Industrial Research (CSIR), HRDG (File No: 09/028(1162)/2020-EMR-I)", (iii) "UGC Basic Science Research Faculty Fellowship" (No.F.18-1/2011(BSR)), and iv) National Post-Doctoral Scheme sponsored by Science and Engineering Research Board, Department of Science and Technology (Grant No. PDF/2020/001561).

\section{Authors' Contributions}

All authors contributed to the supply conception and design. Material preparation, data collection and analysis were performed by [Soumyajyoti Jana], [Gargi Rakshit] and [Animesh Maitra]. All authors read and approved the final manuscript.

Availability of Data and Material: The datasets analysed during the current study are available from the corresponding author on reasonable request.

Code availability: Not applicable.

Compliance with ethical standards

This study follows all the ethical standards and does not violate any of them.

Conflict of interest: The authors declare that they have no conflict of interest.

Consent to participate: Necessary consents from the co-authors are obtained. 
Consent for publication: No permission was required to publish the results incorporated in this paper.

\section{References}

Alexander, M. J., \& Holton, J. R. (1997).A model study of zonal forcing in the equatorial stratosphere by convectively induced gravity waves.Journal of the Atmospheric Sciences, 54(3), 408-419. https://doi.org/10.1175/1520-0469(1997)054<0408:AMSOZF>2.0.CO;2

Alexander, M. J., Holton, J. R., \&Durran, D. R. (1995). The gravity wave response above deep convection in a squall line simulation.Journal of the Atmospheric Sciences, 52(12), 2212-2226. https://doi.org/10.1175/1520-0469(1995)052<2212:TGWRAD>2.0.CO;2

Babu, S. S., Moorthy, K. K., Manchanda, R. K., Sinha, P. R., Satheesh, S. K., Vajja, D. P., ... \& Kumar, V. A. (2011). Free tropospheric black carbon aerosol measurements using high altitude balloon: Do BC layers build "their own homes" up in the atmosphere?. Geophysical research letters, $38(8)$.

De Graaf, M., Stammes, P., Torres, O., \&Koelemeijer, R. B. A. (2005).Absorbing Aerosol Index: Sensitivity analysis, application to GOME and comparison with TOMS. Journal of Geophysical Research: Atmospheres, 110(D1).

Ern, M., Ploeger, F., Preusse, P., Gille, J. C., Gray, L. J., Kalisch, S., ...\&Riese, M. (2014). Interaction of gravity waves with the QBO: A satellite perspective. Journal of Geophysical Research: Atmospheres, 119(5), 2329-2355.

Fritts, D. C., \& Alexander, M. J. (2003). Gravity wave dynamics and effects in the middle atmosphere.Reviews of Geophysics, 41(1), 1003.https://doi.org/10.1029/2001RG000106.

Geller, M. A., \& Gong, J. (2010). Gravity wave kinetic, potential, and vertical fluctuation energies as indicators of different frequency gravity waves. Journal of Geophysical Research: Atmospheres, 115(D11).

Gu, Y., Liao, H., \&Bian, J. (2016). Summertime nitrate aerosol in the upper troposphere and lower stratosphere over the Tibetan Plateau and the South Asian summer monsoon region. Atmospheric Chemistry and Physics, 16(11), 6641.

Hansen, J., Sato, M., \&Ruedy, R. (1997).Radiative forcing and climate response. Journal of Geophysical Research: Atmospheres, 102(D6), 6831-6864.

Huang, J., Wang, T., Wang, W., Li, Z., \& Yan, H. (2014).Climate effects of dust aerosols over East Asian arid and semiarid regions. Journal of Geophysical Research: Atmospheres, 119(19), 11-398.

Holton, J. R. (1983). The influence of gravity wave breaking on the general circulation of the middle atmosphere. Journal of the Atmospheric Sciences, 40(10), 2497-2507. 
Intergovernmental Panel on Climate Change (IPCC), 2001. In: Houghton, J.T., et al. (Eds.), Climate Change 2001: The Scientific basis: Contribution of Working Group I to the Third Assessment Report of the Intergovernmental Panel on Climate Change. Cambridge University Press, New York, 881pp.

Jacobson, M. (2001). Strong radiative heating due to mixing state of black carbon in atmospheric aerosol, Letters to Nature, 409, 695-697.

Jana, S., \& Maitra, A. (2019). Electric field variation in clear and convective conditions at a tropical urban location. Journal of Geophysical Research: Atmospheres, 124(4), 2068-2078.

Jana, S., Rakshit, G., \&Maitra, A. (2020). Gravity Wave Activities Associated With Convective Phenomena at a Tropical Location Near Land-Sea Boundary. Radio Science, 55(1), e2019RS006952.

Kaufman, Y. J., Koren, I., Remer, L. A., Rosenfeld, D., \&Rudich, Y. (2005).The effect of smoke, dust, and pollution aerosol on shallow cloud development over the Atlantic Ocean. Proceedings of the National Academy of Sciences, 102(32), 11207-11212.

Kulkarni, A. V., Bahuguna, I. M., Rathore, B. P., Singh, S. K., Randhawa, S. S., Sood, R. K., \&Dhar, S. (2007). Glacial retreat in Himalaya using Indian remote sensing satellite data. Current science, 69-74.

Koren, I., Kaufman, Y. J., Remer, L. A., \& Martins, J. V. (2004).Measurement of the effect of Amazon smoke on inhibition of cloud formation. Science, 303(5662), 1342-1345.

Lane, T. P., Reeder, M. J., \& Guest, F. M. (2003). Convectively generated gravity waves observed from radiosonde data taken during MCTEX. Quarterly Journal of the Royal Meteorological Society: A journal of the atmospheric sciences, applied meteorology and physical oceanography, 129(590), 1731-1740.

Lau, N. C. (1979). The observed structure of tropospheric stationary waves and the local balances of vorticity and heat. Journal of Atmospheric Sciences, 36(6), 996-1016.

Nair, V. S., Babu, S. S., Gogoi, M. M., \& Moorthy, K. K. (2016). Large-scale enhancement in aerosol absorption in the lower free troposphere over continental India during spring. Geophysical Research Letters, 43(21), 11-453.

Niranjan, K., Madhavan, B. L., \& Sreekanth, V. (2007). Micro pulse lidar observation of high altitude aerosol layers at Visakhapatnam located on the east coast of India. Geophysical Research Letters, 34(3).

Rakshit, G., Jana, S., \& Maitra, A. (2018). Gravity wave behavior in lower stratosphere during tropical cyclones over the Bay of Bengal. Radio Science, 53(11), 1356-1367. 
Ravindra Babu, S., VenkatRatnam, M., Basha, G., Krishnamurthy, B. V., \& Venkateswararao, B. (2015).Effect of tropical cyclones on the tropical tropopause parameters observed using COSMIC GPS RO data. Atmospheric Chemistry and Physics, 15(18), $10,239-10,249$.

Ray, E. A., \& Rosenlof, K. H. (2007).Hydration of the upper troposphere by tropical cyclones. Journal of Geophysical Research: Atmospheres, 112(D12), D12311. https://doi.org/10.1029/2006JD008009

Vincent, R. A., \& Joan Alexander, M. (2000). Gravity waves in the tropical lower stratosphere: An observational study of seasonal and interannual variability. Journal of Geophysical Research: Atmospheres, 105(D14), 17971-17982.

Satheesh, S. K., Moorthy, K. K., Babu, S. S., Vinoj, V., \& Dutt, C. B. S. (2008). Climate implications of large warming by elevated aerosol over India. Geophysical Research Letters, 35(19).

Scargle, J. D. (1982). Studies in astronomical time series analysis.II-Statistical aspects of spectral analysis of unevenly spaced data. The Astrophysical Journal, 263, 835-853.

Stull, R. B. (1995). Meteorology today for scientists and engineers: A technical companion book to meteorology today by C. Donald Ahrens. Eagan, MN: West Publishing Company.

Talukdar, S., Jana, S., \&Maitra, A. (2017). Dominance of pollutant aerosols over an urban region and its impact on boundary layer temperature profile. Journal of Geophysical Research: Atmospheres, 122(2), 1001-1014.

Tao, D., \& Zhang, F. (2015). Effects of vertical wind shear on the predictability of tropical cyclones: Practical versus intrinsic limit. Journal of Advances in Modeling Earth Systems, 7(4), 1534-1553.

Thornhill, G. D., Ryder, C. L., Highwood, E. J., Shaffrey, L. C., \& Johnson, B. T. (2018). The effect of South American biomass burning aerosol emissions on the regional climate. Atmospheric Chemistry and Physics, 18(8), 5321-5342.

Tsuda, T., Ratnam, M. V., May, P. T., Alexander, M. J., Vincent, R. A., \& MacKinnon, A. (2004). Characteristics of gravity waves with short vertical wavelengths observed with radiosonde and GPS occultation during DAWEX (Darwin Area Wave Experiment). Journal of Geophysical Research: Atmospheres, 109(D20).

Venkat Ratnam, M., Tetzlaff, G., \& Jacobi, C. (2004). Global and seasonal variations of stratospheric gravity wave activity deduced from the CHAMP/GPS satellite. Journal of the Atmospheric Sciences, 61(13), 1610-1620. https://doi.org/10.1175/15200469(2004)061<1610:GASVOS>2.0.CO;2 
Vincent, R. A., \& Joan Alexander, M. (2000). Gravity waves in the tropical lower stratosphere: An observational study of seasonal and interannual variability. Journal of Geophysical Research: Atmospheres, 105(D14), 17971-17982.

Wallace, J. M., \& Hobbs, P. V. (2006). Atmospheric science: an introductory survey (Vol. 92). Elsevier.

Yue, X., Schreiner, W. S., Lei, J., Rocken, C., Hunt, D. C., Kuo, Y. H., \& Wan, W. (2010). Global ionospheric response observed by COSMIC satellites during the January 2009 stratospheric sudden warming event. Journal of Geophysical Research: Space Physics, 115(A11). 